ESTUDOS R:EP

\title{
Sistema e Plano Nacional de Educação: notas sobre conceituação, relação público-privado e financiamento
}

Maria Dilnéia Espíndola Fernandes

Silvia Helena Andrade de Brito

Vera Maria Vidal Peroni

\section{Resumo}

Problematiza as articulações entre o Sistema Nacional de Educação (SNE) e o Plano Nacional de Educação (PNE 2011-2020), analisando a legislação educacional e os documentos da Conferência Nacional de Educação (Conae 2010), cotejados com as fontes secundárias. Nesse processo, destacam-se três contradições: a primeira inclui a definição acerca do que seria o SNE; a segunda, as relações entre público e privado, mostrando a ascendência deste último na política educacional; e a terceira abrange o financiamento, revelando um Estado que atende o mercado e administra com escassez monetária.

Palavras-chave: Estado; direito educacional; financiamento da educação. 


\section{Abstract}

The National System of Education and the National Plan for Education: notes on conceptualization, the public/private relationship, and financing

The paper deals with the articulations between the National System of Education (SNE) and the National Plan for Education (PNE 2011-2020), by analyzing the educational legislation and documents from Conae 2010, and by comparing them with secondary sources. Three contradictions are highlighted in the process. The first one includes the definition of the SNE. The second one shows the relationships between public and private, with an indication that the latter influences on educational policies. The third contradiction refers to financing, and unveils the fact that the State meets the market demands and administers with monetary scarcity.

Keywords: State; educational right; educational financing.

\section{Introdução}

Este trabalho aborda alguns desafios que se engendram no atual momento histórico, considerando as articulações em torno do Sistema Nacional de Educação (SNE) e o debate para a aprovação do Plano Nacional de Educação (PNE), com vigência no período de 2011 a 2020.

Destacamos aqui contradições que permeiam a possibilidade de construção de um SNE, tais como: as implicações inscritas na própria conceituação e abrangência do SNE; as relações entre público e privado; e o financiamento da educação básica brasileira, particularmente quanto aos recursos destinados à Manutenção e Desenvolvimento do Ensino (MDE) e seus consequentes desenhos no PNE vindouro.

A definição acerca do que seria um SNE, nas condições peculiares à educação no Brasil, é um dos temas a ser enfrentado no próximo decênio. Apesar da incorporação do próprio conceito no aparato jurídico brasileiro, indefinições ainda estão presentes na atual conjuntura, entre elas destacamos aquelas que se referem ao papel do SNE ante a escola privada ou aquelas relativas ao regime de colaboração entre os entes federados.

A temática sobre público e privado vem sendo uma das contradições mais relevantes, na medida em que tal situação tem sido um dos obstáculos à construção de um SNE, dado que o Estado brasileiro historicamente tem se eximido de garantir o direito à educação para todos. Diante disso, cada vez mais, observamos o setor privado mercantil influenciando a política educacional. Exemplos disso têm sido as parcerias entre instituições do 
terceiro setor e sistemas públicos de ensino, quando a coordenação de todo o processo educacional, desde a gestão até o currículo, passa a ser definida pela instituição privada, imprimindo no público a lógica mercantil.

Já a temática do financiamento da educação básica, ao tempo em que materializa limites e possibilidades para concretizar o direito à educação, desvela também os liames que perpassam as relações entre público e privado, à medida que o setor privado, via de regra, entende que seu financiamento deve se dar com recursos públicos. Situação que revela uma das contradições fundamentais para a construção de um SNE, pois, se por um lado o Estado se coloca como provedor da política educacional, por outro, ao injetar recursos públicos no setor privado educacional, administra o setor com escassez monetária, o que retrai o direito à educação pública.

Para o desenvolvimento dessas reflexões, este trabalho baseia-se na legislação educacional, nas pesquisas que desenvolvemos sobre as temáticas aqui elencadas, nos subsídios para o documento final da Conferência Nacional de Educação 2010 (Conae), nos atos dos Poderes Executivo e Legislativo nacionais e na literatura pertinente à temática.

\section{Desafios (ainda) postos pela Conae e pelo PNE para uma definição acerca do Sistema Nacional de Educação}

A primeira parte do presente texto tem como objetivo apresentar algumas considerações sobre os desafios postos à constituição de um SNE, tendo como base as referências explicitadas no Documento Final da Conae (Brasil. Conae, 2010) e no Projeto de Lei no 8.035/2010, ora em tramitação no Congresso Nacional, que diz respeito ao novo PNE.

Uma primeira questão aflora quando nos deparamos com a temática proposta para a discussão na Conae, a saber: "Construindo o Sistema Nacional Articulado: o Plano Nacional de Educação, Diretrizes e Estratégias de Ação". Esta, lembrada por Saviani (2010), diz respeito ao pleonasmo presente na expressão "sistema nacional articulado [de educação]". Baseado numa argumentação visando precisar o significado último da categoria "sistema", entendido como "[...] unidade de vários elementos intencionalmente reunidos de modo a formar um conjunto coerente e operante", lembra-nos o autor ser impossível, isto posto, que exista um sistema que não pressuponha entre seus atributos o de ser articulado. Nesse sentido, lembram Saviani (2009; 2010) e Cury (2008), a bem da verdade, que a questão posta à educação brasileira estaria mais bem definida quando se pensasse na necessidade de construção mesma de um SNE.

Assim, uma primeira constatação deve ser destacada: entre a proposição dos primeiros debates, ainda em 2008, que envolveram a preparação para a Conae, e o texto do documento final da Conferência, em 2010, interpôs-se a urgência em se enfrentar tal desafio a partir de duas iniciativas. Primeiro, o conceito de SNE foi incorporado na Emenda Constitucional no 59 (Brasil. Emenda..., 2009), que, entre outras medidas, 
deu nova redação ao art. $\mathrm{n}^{\circ} 214$ da Constituição Federal, que trata exatamente da elaboração do PNE, a ser executada no ano seguinte; segundo, em consequência da primeira iniciativa, o documento que sintetizou os resultados da Conae 2010 voltou a tratar do tema, até porque a referida Emenda Constitucional já afirmara a relação intrínseca entre o PNE e o próprio SNE, visto que o PNE balizaria as ações a serem desenvolvidas visando fortalecer o próprio SNE (Brasil. Conae, 2010).

Essa premissa, ou seja, o reconhecimento pelo Estado da lacuna a ser enfrentada pela educação no Brasil no sentido de sua constituição enquanto sistema, não seria suficiente, no entanto, para resolver outras questões fundamentais decorrentes desta, como lembram os citados autores (Saviani, 2009, 2010; Cury, 2008). Entre essas questões destacaremos duas, que serão por nós esboçadas a seguir. Colocadas em termos históricos, elas se constituiriam em desafios ainda postos à construção de um SNE no País.

A primeira delas, destacada por Cury, poderia ser englobada sob a bandeira da busca de uma escola única. Essa unicidade, em nosso entender, remete à perspectiva de Gramsci (2006, p. 49 - grifos nossos) de que tal tipo único de escola seja a "que conduza o jovem até os umbrais da escolha profissional, formando-o, durante este meio tempo, como pessoa capaz de pensar, de estudar, de dirigir ou de controlar quem dirige."

Gramsci (2006, p. 49) lembra que, contrariamente à almejada escola única, a marca social da escola ainda hoje presente está dada pelo fato de que cada grupo social "[tenha] um tipo de escola própria, destinado a perpetuar nestes extratos uma determinada função tradicional, dirigente ou instrumental". Cury lembra, é importante frisarmos, que o desafio de constituição de um sistema nacional com tal característica, não marcadamente classista, permanecerá, visto tratar-se de perspectiva a ser vencida pari passu com a superação do próprio capitalismo, sociedade que alimenta e se alimenta dessa estrutura. O que não nos afasta, contudo, do desafio de "[...] consecução [destes] valores, princípios e normas comuns, além de normas específicas, afirmados no ordenamento jurídico atual" (Cury, 2008, p. 13), implicando, assim, a disputa pela construção de um projeto educacional que dê consequência prática a tais princípios.

Ainda como resultados dessa dinâmica historicamente construída da busca de uma escola única, duas consequências, contraditórias e contraditoriamente postas, são destacadas por Cury: por um lado, o alargamento progressivo do que veio a se configurar como a educação básica, o que importou no imperativo de que o Estado assumisse, de forma orgânica, o processo de expansão e manutenção dessa escola. Como única instituição social capaz de imprimir caráter geral a esse processo (Saviani, 2009), o fortalecimento da organicidade do sistema foi um imperativo ao qual o poder estatal, em alguma medida, teve que responder. Por outro lado, isso não significou, contudo, a constituição de diretrizes capazes de impor o interesse público, entendido este último como interesse da maioria (Sanfelice, 2005), por sobre os interesses privados. Nesse sentido, embora colocado como o dirigente maior de uma organização que se pretende 
conduzida pelos mesmos princípios e bases, o Estado aparece, ante ao setor privado, principalmente como aquele que garante a validade de seus certificados e diplomas, visto que lhe cabe juridicamente dar o aval para funcionamento de instituições e estabelecimentos escolares.

Não por acaso e muito significativamente, nas três primeiras metas previstas para o novo PNE (Brasil. Projeto..., 2010) - todas referentes à educação básica e que se desdobram em 9, 12 e novamente 12 estratégias -, tão somente duas são diretamente dirigidas à esfera privada, sendo que ambas dizem respeito, por certo, à questão mercadológica. A primeira, ligada à educação infantil, visa "estimular a oferta de matrículas gratuitas em creches por meio da concessão de certificado de entidade beneficente de assistência social na educação" (p. 4). A segunda, relacionada à educação profissional, diz respeito à expansão do programa de financiamento da educação profissional, por meio da concessão de financiamento estudantil a entidades privadas nessa modalidade de ensino. Lembramos aqui a referência, ainda em seu discurso de posse, a $1^{\circ}$ de janeiro de 2011 , da presidente Dilma Roussef, quando fazia menção ao financiamento de uma modalidade de "ProUni" para o ensino profissional privado de nível médio.

O segundo desafio ainda posto à construção de um SNE no País refere-se à modalidade de articulação existente entre os entes federativos. Como lembra Cury (2008, p. 17-18):

\begin{abstract}
Ora, essa tradição de mais de 164 anos foi criando e sedimentando uma cultura relativa à autonomia dos entes federados, sobretudo dos Estados, no âmbito da educação escolar. Tal tradição se apóia não só na maior proximidade entre as fases de vida próprias da educação básica e os gestores das administrações estaduais e municipais, mas também nas relações de poder que os vastos sistemas de ensino propiciam face a cargos e funções. Nesse sentido, temos uma organização da educação nacional e não um sistema nacional. Nacional é a educação, na forma federativa em que comparecem competências privativas, concorrentes e comuns dos entes federativos.
\end{abstract}

Assim, para Cury, além do desafio já constatado diante do setor privado, a questão das relações entre as esferas do poder estatal - União, Estados e municípios - também permanece aberta. Na verdade, diferentes autores (Cury, 2008; Barreto, 1988) apontam a necessidade de que seja estabelecido com clareza o regime de colaboração entre as três esferas do poder estatal, que, embora previsto no $\S 3^{\circ}$, art. 23 da Constituição, até o momento não foi regulamentado. ${ }^{1}$ Para Saviani (2009, p. 29), trata-se de estabelecer claramente uma

\footnotetext{
repartição das responsabilidades entre os entes federativos, todos voltados para o mesmo objetivo de prover uma educação com o mesmo padrão de qualidade a toda a população brasileira. Assim, deixam de ter sentido os argumentos contra o sistema nacional baseados no caráter federativo que pressupõe a autonomia de estados e municípios. O regime de colaboração é um preceito constitucional que, obviamente não fere a autonomia dos entes federativos.
}

1 A questão do regime de colaboração, particularmente no que se refere à MDE, será melhor analisada na terceira parte deste trabalho. 
Ora, na falta de uma regulamentação precisa e considerando-se as relações de poder condizentes com uma sociedade de classes como a capitalista, criam-se as condições propícias para o que Cury denomina de "federalismo competitivo", envolvendo a guerra fiscal entre os Estados, a permanente discussão entre o que pode ou não ser investido em cada esfera e a possibilidade de sonegação de parte das receitas vinculadas, como é o caso do uso de artifícios, a exemplo da caracterização de impostos como "contribuições e fundos", entre outros. Em outras palavras, quanto menor o controle da sociedade civil sobre o Estado, tanto mais desfavoráveis as possibilidades de se construir as bases para um sistema nacional no campo educacional.

Assim, consideradas essas condições para a efetivação de um SNE, passamos a abordar, de forma mais detalhada, o desafio aberto quando se trata de problematizar as relações entre as esferas pública e privada, no âmbito de um SNE.

\section{Conexões entre o público e o privado e o Sistema Nacional de Educação}

Ao tratar do tema público-privado no planejamento a longo prazo no Brasil (documento da Conae e Projeto de PNE), a questão central não é apenas a propriedade, mas o conteúdo da política pública de educação. Como diz Zeca Baleiro (2005), "a alma é o segredo do negócio", e o setor vinculado ao mercado já descobriu isso e vem trabalhando arduamente para que a "lógica" e o "espírito empreendedor" estejam na coordenação das políticas educacionais em todo o mundo.

As nossas pesquisas nos últimos anos vêm tratando de como as redefinições no papel do Estado materializam-se nas políticas educacionais, principalmente nas fronteiras entre o público e o privado, por meio do estudo da relação entre o terceiro setor mercantil e os sistemas públicos de ensino e suas consequências para a democratização da educação. Constatamos que o setor privado, nos últimos anos, cada vez mais interfere no setor público como parte de um diagnóstico de que o Estado é ineficiente e o setor privado mercantil deve ser o coordenador da vida em sociedade.

Entendemos que a política educacional compõe a materialização do Estado em um determinado período e que, por sua vez, é parte do movimento histórico em um momento particular do capitalismo. Assim, concordamos com Vieira (2007), quando afirma que a "política econômica e a política social relacionam-se intimamente com a evolução do capitalismo" e "qualquer exame da política econômica e da política social deve fundamentar-se no desenvolvimento contraditório da história" e, nesse sentido, "em nível lógico, tal exame mostra as vinculações destas políticas com a acumulação capitalista. Em nível histórico, verifica se consistem em respostas às necessidades sociais, satisfazendo-as ou não" (Vieira, 2007, p. 136). 
O Estado, portanto, não é concebido como uma abstração, mas como parte importante da correlação de forças de um dado período histórico, como afirma Vieira (2007, p. 144):

Não tem havido, pois, política social desligada dos reclamos populares. Em geral, o Estado acaba assumindo alguns destes reclamos, ao longo de sua existência histórica. Os direitos sociais significam antes de mais nada a consagração jurídica de reivindicações dos trabalhadores. Não significam a consagração de todas as reivindicações populares, e sim a consagração daquilo que é aceitável para o grupo dirigente no momento.

Sendo assim, é importante analisar a política educacional atual no contexto da redefinição do papel do Estado, que, por sua vez, está inserida em um movimento maior do capitalismo, no qual, na tentativa de superar sua crise, foram estabelecidos como estratégias principais o neoliberalismo, a globalização, a reestruturação produtiva e a terceira via. Estratégias essas que acabaram redefinindo as fronteiras entre o público e o privado tanto na alteração da propriedade (público não estatal) quanto no que permanece na propriedade estatal, mas passa a ter a lógica do mercado, reorganizando os processos de gestão (quase-mercado) (Peroni, 2003, 2006, 2007).

Esse processo tem implicações nas políticas educacionais e, mais especificamente, na parceria público-privada, que acaba por redefinir o conteúdo das políticas públicas de educação. É a lógica privada mercantil no sistema público, influenciando tanto a gestão quanto o currículo das escolas.

Portanto, no momento em que está em pauta a instituição de um SNE, este debate adquire muita importância, já que a correlação de forças entre os setores para definir os rumos da educação no País acaba adquirindo um caráter institucional.

Por isso, entre os principais desafios para a construção do SNE está a relação entre o setor público e o privado e entre os entes federados, principalmente o papel da União na educação básica, que historicamente esteve praticamente ausente. As questões estão muito conectadas, já que historicamente Estados e municípios assumiram a execução da educação básica de forma descentralizada, o que reproduziu as desigualdades regionais, pois Estados e municípios com mais recursos financeiros e com quadros capacitados para a elaboração de políticas tinham formas muito diversas de oferta e qualidade do que aqueles sem as mesmas condições. Assim, um dos principais desafios para a criação do SNE é pensar o País como um todo, com políticas públicas que garantam a democratização da educação tanto na oferta e na qualidade quanto na gestão do processo. É um desafio enorme, pois é totalmente novo na nossa história, mas, por correr o risco de centralizar e desrespeitar o pacto federativo, esse processo necessita ser construído coletivamente e com participação efetiva nas decisões.

Mas acreditamos que existem projetos educativos em disputa, e, assim, os interlocutores do Estado e da sociedade civil organizada que 
estiverem na coordenação da elaboração das políticas educacionais assumirão significativa importância. Portanto, a composição do Fórum Nacional de Educação (FNE), instituído pela Portaria $n^{\circ}$ 1.407, de 14 de dezembro de 2010, passa a ter importância fundamental, já que a correlação de forças no momento atual é diferente da existente no momento em que tal Fórum foi pensado, ainda durante o período de democratização do País, pelo Fórum em Defesa da Escola Pública, no processo constituinte (1987-1988). Naquele período, as forças vinculadas à democratização do Estado e particularmente à educação estavam em um momento de grande ascensão, apesar de já vivermos, principalmente nos países centrais, a retirada do Estado na consecução de direitos materializados em políticas sociais. Para a teoria neoliberal e para a terceira via - aqui entendida como a atual social-democracia - as políticas sociais são um verdadeiro saque à propriedade privada, pois são formas de distribuição de renda (Peroni, 2003).

O neoliberalismo propõe o Estado mínimo e a terceira via propõe reformar o Estado e repassar tarefas para a sociedade civil, sem fins lucrativos. Os dois almejam racionalizar recursos e diminuir os gastos do Estado com as políticas sociais e retrair o papel das instituições públicas, que são permeáveis à correlação de forças, já que o Estado foi diagnosticado como ineficiente e o "culpado" pela crise. Como não rompe com esse diagnóstico, a terceira via propõe repassar para a sociedade civil as políticas sociais executadas pelo Estado e historicamente conquistadas pela sociedade civil organizada em sindicatos e movimentos sociais (Peroni, 2007).

O papel do Estado em relação às políticas sociais é alterado, pois com este diagnóstico duas são as prescrições: racionalizar recursos e esvaziar o poder das instituições, já que instituições democráticas são permeáveis às pressões e demandas da população, além de serem consideradas como improdutivas pela lógica de mercado. Assim, a responsabilidade pela execução das políticas sociais deve ser repassada para a sociedade: para os neoliberais, através da privatização (mercado), e, para a terceira via, pelo público não estatal (sem fins lucrativos) (Peroni, 2006).

É nesse contexto que estamos instituindo o SNE no Brasil, o que não deixa de ser uma contraposição a essa tendência, já que em tempos de retirada do poder público da execução de políticas essa criação pode indicar a maior presença do Estado na coordenação das políticas educacionais para garantir a democratização da educação no País. Mas o contexto apresentado pode indicar uma forte presença do setor privado mercantil influenciando a coordenação da educação nacional. Portanto, urge um debate mais aprofundado sobre a função social da escola hoje.

Sabemos que debater a função social da escola requer que se pense a sua materialidade. Por isso mesmo discutiremos a seguir a política educacional vinculada à perspectiva do seu financiamento, pois concordamos com Wood (2003) que a democracia pode ser uma abstração quando separamos o econômico e o político. Assim, para que os direitos sociais se materializem em políticas necessitamos garantir padrões de 
financiamento. Portanto, acreditamos ser fundamental o debate acerca do financiamento da escola pública no âmbito da instituição do SNE e do PNE.

\section{Equacionamentos no financiamento para a educação básica e o Sistema Nacional de Educação}

Nos documentos anteriormente citados, apresentados para subsidiar as discussões preparatórias da Conae, realizada em abril de 2010, com vista à construção do SNE e do PNE, Cury pontuou que, embora avanços tenham sido conquistados na educação escolar, entre eles o disciplinamento do financiamento, há muito que fazer para ampliar o direito à educação. Saviani também lembrava que, entre os obstáculos à construção do SNE no Brasil, encontrava-se o econômico, que permeia a "histórica resistência à manutenção da educação pública no Brasil" (Saviani, 2009, p. 16).

De fato, a questão do financiamento para a educação básica brasileira, em todas as suas modalidades de ensino, tem se colocado historicamente como um dos grandes empecilhos na construção de um sistema nacional de ensino. E essa tem sido uma das causas de obstacularização nos planos nacionais de educação, tanto em sua concepção quanto em sua execução. Nesse processo residem muitas das causas que têm interferido negativamente na construção de um SNE, pois exatamente o âmbito do financiamento da educação tem sido um dos percalços que desafia a articulação entre os entes federados e, de forma consequente, a oferta e a garantia do ensino.

Sabemos que a vinculação constitucional de recursos para a MDE, disposta na Constituição Federal de 1988 e normatizada pela legislação infraconstitucional (Brasil, 2001), embora tenha garantido recursos mínimos de impostos anuais para financiá-la, não tem sido suficiente para garantir um padrão de qualidade da educação básica brasileira.

Da mesma forma, as políticas de fundos, como o Fundo de Manutenção e Desenvolvimento do Ensino Fundamental e de Valorização do Magistério (Fundef) e o Fundo de Manutenção e Desenvolvimento da Educação Básica e de Valorização dos Profissionais da Educação (Fundeb) (Brasil, 2001, 2007), vêm operando com os valores resultantes da vinculação constitucional de recursos para financiar a MDE. Obviamente que tanto o Fundef quanto o Fundeb operaram, no âmbito das finanças públicas, uma maior transparência na aplicabilidade do uso dos recursos para a MDE, melhoraram seus mecanismos de gestão, possibilitaram também a instituição de um valor/aluno/ano mínimo em cada unidade federada e ainda instituíram processos de controle social para os recursos voltados à MDE.

Ao tempo em que o Fundef intensificou processos de descentralização e de municipalização na política educacional para o ensino fundamental, o Fundeb resgatou o conceito de educação básica no campo do financiamento para a MDE, não obstante o gasto total nacional em educação permanecer ao longo dos últimos vinte anos do século 20 e primeira década do século 21 em torno de 4,3\% do Produto Interno Bruto (PIB) do País (Pinto, 2007). O gasto de 4,3\% do PIB em educação no Brasil tem sido considerado como uma forma "histórica [de] resistência à manutenção da educação pública 
no Brasil" (Saviani, 2009, p. 16). Por isso mesmo, no Projeto de Lei que encaminhou o PNE para aprovação pelo Congresso Nacional, encontra-se em pauta o limite de 7\% do PIB para financiar a educação pública.

Trata-se de uma proposta para aumentar os recursos para a educação. Não obstante, compreendemos que, no caso brasileiro, o impacto de tal medida, para alcançar os objetivos elencados, deve ser inserido em um conjunto de arranjos institucionais, entre eles a normatização do regime de colaboração, já considerado anteriormente, e a reforma tributária (Araújo, 2010), sem os quais poderia ser prejudicada a construção de um SNE.

Por tudo isso, problematizamos, a partir da legislação educacional e da literatura pertinente, que, embora seja muito bem-vindo o aumento de recursos para a educação, ele sozinho não é suficiente para a construção de uma educação de qualidade. Nosso entendimento é que as contradições que se expressam na relação Estado e sociedade brasileira, embora muitas delas ligadas ao campo do financiamento da educação, o ultrapassam em larga medida e exigem tomadas de decisões em outras esferas de atuação societária.

De fato, como argumentam Gouveia e Souza (2010, p. 792-793), refletindo sobre perspectivas e desafios no âmbito da gestão e do financiamento no contexto da Conae com vista a um novo PNE:

As proposições [da Conae] dedicam-se a garantir incremento de condições de financiamento da educação a partir de diferentes subtemáticas: a vinculação de recursos para educação pública; participação da União no financiamento da educação; equidade de gastos; o uso dos recursos vinculados; necessidade de uma reforma tributária com justiça social; fiscalização e publicização dos investimentos; política de fundos; integração de políticas sociais; controle sobre a iniciativa privada; autonomia das unidades escolares.

Destacamos aqui, para o contexto do financiamento da educação básica e objetivando problematizar a forma como se efetivará o PNE e cotejando-o com o Documento Final da Conferência (Brasil. Conae, 2010), as perspectivas que se abrem e os desafios que se impõem no âmbito das relações federativas brasileiras.

Se por um lado as relações federativas conceitualmente são definidas pela autonomia entre os entes federados e, por outro, pela interdependência entre eles, cabe inferir que, no que tange à autonomia de cada um para o campo do financiamento da educação, se encontra a possibilidade de ir além dos mínimos historicamente praticados; no que se refere às vinculações constitucionais de recursos, sabemos que a União, os Estados e os municípios sempre ficaram senão aquém de aplicar os recursos financeiros mínimos vinculados, no limite do que está disposto na legislação educacional.

É conhecido o fato de que alguns Estados e municípios, à época da elaboração de suas constituições estaduais e leis orgânicas municipais (1989 e 1990, respectivamente), ousaram vincular recursos para a MDE a mais do que o disposto na Constituição Federal de 1988. Tais unidades subnacionais, contudo, a partir dos rearranjos impostos pelas políticas de 
fundos (Fundef e Fundeb), reorganizaram suas legislações, voltando aos patamares do dispositivo da Constituição Federal para financiar a MDE.

Agora, com o aumento de gastos para 7\% do PIB proposto para a educação - caso seja aprovado pelo Poder Legislativo e não seja vetado pelo Poder Executivo no novo PNE -, a possibilidade se coloca ao mesmo tempo em que o desafio: União, Distrito Federal, Estados e municípios terão que se haver com determinações importantes para a materialização da política educacional com a ampliação de recursos. Tais determinações não se encontram somente na esfera da política educacional, mas também para além dela.

Esperamos que a perspectiva da construção do SNE equacione essas questões do âmbito do financiamento, pois dela decorrem - ainda que não de maneira exclusiva e definitiva - outros percalços que influenciam na construção de uma educação pública de qualidade, como formação de professores e suas condições materiais de existência, a gestão democrática do ensino, o controle social da educação, entre outros temas tão caros ao propósito educacional.

\section{"Nada deve parecer natural, nada deve parecer impossível de mudar" (B. Brecht)}

Tendo como foco de nossas preocupações alguns dos desafios considerados fundamentais para a constituição de um SNE no Brasil, lembramos a importância desse momento histórico em que, apesar das contradições ora explanadas, e, como faz menção Saviani (2010), está em jogo mais uma oportunidade ímpar para a disputa em torno de um projeto de defesa de educação para todos.

Por isso torna-se fundamental a menção ao caráter radicalmente histórico que imprimimos à presente discussão, lembrada ao início desta parte do trabalho pelas palavras do teatrólogo alemão Bertolt Brecht (1982): que não pareça natural aquilo que é fruto da luta entre homens constituídos e organizados em uma sociedade dividida em classes, organizados de forma mais ou menos conscientes em torno de distintas concepções de mundo, de homem e de sociedade. No interior desse processo, definições como aquelas que orientarão temas fundamentais para o SNE ora em construção, balizado pelo PNE para o decênio que se inicia, tais como a abrangência do sistema, a relação entre as esferas pública e privada ou a questão do financiamento não deverão se constituir a partir de uma suposta - e muitas vezes almejada - naturalização que esconde sua condição de produto da ação humana.

Da mesma forma, sua condição de produtos da ação humana recoloca seu caráter de coisas em constante processo de transformação, aliás, marca característica de tudo o que é fruto do trabalho do homem em sua incessante necessidade de construir e reconstruir sua humanidade. Visto dessa forma, se é possível reconhecer a possibilidade de constituição de um SNE, é imperioso também afirmar sua condição de um todo orgânico, contraditório e em movimento, no qual as referências que garantirão a escola única, voltada para o interesse da maioria e, portanto, devidamente 
sustentada materialmente e afirmada nas tradições de luta da classe trabalhadora estão ainda no horizonte das disputas em palco na sociedade capitalista que inicia o segundo decênio do século 21 .

\section{Referências bibliográficas}

ARAÚJO, G. C. de. Constituição, federação e propostas para o novo Plano Nacional de Educação: análise das propostas de organização nacional da educação brasileira a partir do regime de colaboração. Educação \& Sociedade, Campinas, v. 31, n. 112, p. 749-768, jul./set. 2010. Disponível em: <http://www.scielo.br/pdf/es/v31n112/06.pdf>.

BALEIRO, Zeca. Balada do asfalto. In: Baladas do asfalto e outros blues. São Paulo: MZA/Universal Music, 2005. Disponível em: < http://zecabaleiro.locaweb.com.br/sitezeca/discografia/discos_ autorais/letras/baladas/02.htm>. Acesso em: 8 jan. 2011.

BARRETO, E. S. de S. O ensino fundamental na política nacional de Educação: alguns aportes. Em Aberto, Brasília, v. 7, n. 38, p. 12-21, abr./jun. 1988. Disponível em: <http://emaberto.inep.gov.br/index.php/ emaberto/article/viewFile/649/576>.

BRASIL. Câmara dos Deputados. Comissão de Educação, Cultura e Desporto. Coordenação de Publicações. LDB \& Lei do Fundef. Brasília, 2001.

Constituição Federal de 1988. Diário Oficial da República Federativa do Brasil, Brasília, 5 out. 1988.

. Emenda Constitucional no 59, de 11 de novembro de 2009. Acrescenta $\S 3^{\circ}$ ao art. 76 do Ato das Disposições Constitucionais Transitórias para reduzir anualmente, a partir do exercício de 2009, o percentual da Desvinculação das Receitas da União incidente sobre os recursos destinados à manutenção e desenvolvimento do ensino de que trata o art. 212 da Constituição Federal, dá nova redação aos incisos I e VII do art. 208, de forma a prever a obrigatoriedade do ensino de quatro a dezessete anos e ampliar a abrangência dos programas suplementares para todas as etapas da educação básica, e dá nova redação ao $\S 4^{\circ}$ do art. 211 e ao $\S 3^{\circ}$ do art. 212 e ao caput do art. 214, com a inserção neste dispositivo de inciso VI. Disponível em: < http:// www.planalto.gov.br/ccivil_03/constituicao/emendas/emc/emc59.htm>. Acesso em: 8 jan. 2011.

. Lei no 11.494 de 20 de junho de 2007. Regulamenta o Fundo de Manutenção e Desenvolvimento da Educação Básica e de Valorização dos Profissionais da Educação - FUNDEB, de que trata o art. 60 do Ato 
das Disposições Constitucionais Transitórias. 2007. Disponível em: <http://www.planalto.gov.br/ccivil_03/_Ato20072010/2007/Lei/L11494. htm>. Acesso em: 29 mar. 2010.

Projeto de Lei $n^{\circ}$ 8.035/2010. Aprova o Plano Nacional de Educação para o decênio 2011-2020. Brasília: 2010. Disponível em: $<$ http://conae.mec.gov.br/index.php?option $=$ com_content\&view $=$ article \&id=363: pne\&catid=100:mais-noticias > . Acesso em: 8 jan. 2011.

BRASIL. Conferência Nacional de Educação (Conae). Documento final. Brasília, 2010. Disponível em: <http://conae.mec.gov.br/images/stories/ pdf/pdf/documetos/documento_final_sl.pdf $>$.

BRASIL. Ministério da Educação. Portaria no 1.407, de 14 de dezembro de 2010. Institui o Fórum Nacional de Educação - FNE. Disponível em: $<$ http://cedes.org.br>. Acesso em: 10 jan.2011.

BRECHT, B. Antologia poética de Bertolt Brecht. 3. ed. Rio de Janeiro: Elo, 1982.

CURY, C. R. J. Os desafios da construção de um Sistema Nacional de Educação. Brasília: 2008. Disponível em: <http://conae.mec.gov.br/ images/stories/pdf/jamil_cury.pdf>. Acesso em: 05 abr. 2010.

GOUVEIA, A. B.; SOUZA, A. R. de. Perspectivas e desafios no debate sobre financiamento e gestão da educação: da Conae ao novo PNE. Educação \& Sociedade, Campinas, v. 31, n. 112, p. 789-807, jul./set. 2010. Disponível em: < http://www.scielo.br/pdf/es/v31n112/08.pdf>.

GRAMSCI, A. Cadernos do cárcere. 4. ed, v. 2. Rio de Janeiro: Civilização Brasileira, 2006.

MORAES, R. Neoliberalismo: de onde vem, para onde vai? São Paulo: Senac, 2001.

PINTO, J. M. de R. A política recente de fundos para o financiamento da educação e seus efeitos no pacto federativo. Educação \& Sociedade, v. 28, n. 100, p. 877-898, out. 2007. Disponível em: < http://www. scielo.br/pdf/es/v28n100/a1228100.pdf>.

PERONI, V. M. V. Política educacional e papel do Estado no Brasil dos anos 90. São Paulo: Xamã, 2003.

. Mudanças na configuração do Estado e sua influência na política educacional. In: PERONI, V. M. V.; BAZZO, V. L.; PEGORARO, L. (Orgs.). Dilemas da educação brasileira em tempos de globalização neoliberal: entre o público e o privado. Porto Alegre: Edufrgs, 2006. 
PERONI, V. M. V. Reforma do Estado e a tensão entre o público e o privado. Revista SIMPE-RS, Porto Alegre, p. 11-33, 2007.

SANFELICE, J. L. Da escola estatal burguesa à escola democrática e popular: considerações historiográficas. In: LOMBARDI, J. C.; SAVIANI, D.; NASCIMENTO, M. I. M. (Orgs.). A escola pública no Brasil: história e historiografia. Campinas: Autores Associados, 2005. p. 89-105.

SAVIANI, D. Sistema de educação: subsídios para a conferência nacional de educação. Brasília: 2009. Disponível em: <http://conae. mec.gov.br/images/stories/pdef/conae_dermevalsaviani.pdf $>$. Acesso em: 05 abr. 2010.

. Sistema nacional de educação articulado ao Plano Nacional de Educação. Revista Brasileira de Educação, v. 15, n. 44, p. 380-393, maio/ago 2010.

VIEIRA, E. Os direitos e a política social. 2. ed. São Paulo: Cortez, 2007.

WOOD, E. M. Democracia contra o capitalismo: a renovação do materialismo histórico. São Paulo: Boitempo, 2003.

Maria Dilnéia Espíndola Fernandes, doutora em Educação pela Universidade Estadual de Campinas (Unicamp), é professora associada do Programa de Pós-Graduação em Educação da Universidade Federal de Mato Grosso do Sul (UFMS).

mdilneia@uol.com.br

Silvia Helena Andrade de Brito, doutora em Educação pela Universidade Estadual de Campinas (Unicamp), é professora-pesquisadora da Universidade Federal de Mato Grosso do Sul (UFMS), no Programa de Pós-Graduação em Educação.

shbrito@terra.com.br

Vera Maria Vidal Peroni, doutora em Educação pela Pontifícia Universidade Católica de São Paulo (PUC-SP), é professora-pesquisadora da Universidade Federal do Rio Grande do Sul, no Programa de PósGraduação em Educação.

veraperoni@yahoo.com.br

Recebido em 22 de julho de 2011.

Aprovado em 18 de abril de 2012. 